\title{
Building constructions: architecture and nature
}

\author{
Irina Mayatskaya ${ }^{1, *}$, Batyr Yazyev $^{1}$, Svetlana Yazyeva $^{1}$ and Polina Kulinich $^{2}$ \\ ${ }^{1}$ Don State Technical University, pl. Gagarina, 1, Rostov-on-Don, 344010, Russia \\ ${ }^{2}$ North Caucasus Federal University, Stavropol, Russia
}

\begin{abstract}
The problem of optimization of building structures is considered in architectural bionic modeling on the bionic principle basis. It is possible to get a reliable and durable constructions by studying the structure and the laws of organization of natural objects. Modern architects have created unique buildings using the bionic approach. There are such properties as symmetry, asymmetry, self-similarity and fractality used in the modern architecture. Using the methods of fractal geometry in the design of architectural forms allows finding a variety of constructive solutions.
\end{abstract}

\section{Introduction}

In the field of architectural bionics two following methods are applied: direct coping of the laws of nature and modeling of the main stages of development and improvement of designs, shapes, structures of biological objects on the basis of the laws of the evolution of scientific and technical means. The principles and stages of development of architectural bionic modeling are considered in [1-3].

Development of architectural and construction bionics takes place in two directions: the study of the laws and principles of formation, law of organization of biological objects, architectonic plants and living organisms and the use of these properties in the architecture; study of the structure of structural systems of biological objects on the basis of savings in material, energy, and reliability of building structures.

If architects in the first direction used laws of the structure in their buildings, the designers in the second direction are used the benefits of biological objects deficiently.

In this study, attention is paid to the unique facilities, which to use the natural fractal forms with the properties of symmetry, asymmetry and self-similarity.

The problems of improving the design of architectural bionics methods, which makes it possible to use in structures and their elements, principles of organization, properties, functions and structure of wildlife.

\section{Fractals and plant forms}

${ }^{*}$ Corresponding author: irina.mayatskaya@mail.ru 
Let us consider the possibility of applying fractal geometry methods. The concept of fractal (from the Latin: Fractus - consisting of fragments, crushed, broken) proposed to Benua Mandelbrot in 1975 to describe nonregular, self-similar structures [4].

At its simplest case, a small part the fractal contains information about all the fractal. Definition given by by Mandelbrot "Fractal is a structure consisting of parts that are in some sense similar to the whole." The property of self-similarity is found in nature very often, for example, the coast line, mountains, clouds, the trees[5, 6].

There are the methods of fractal geometry, which studies the regularities manifested in the structure of natural objects and phenomena, with pronounced fragmentation and the ruptured characteristic are convenient to resort in the modeling of plant objects $[7,8]$.

For modeling leafy plant is convenient to use the method of " Iterated Functions System " (IFS) as means of reception fractal structures.

The method is based on the serial iterative calculation of the coordinates of new points:

$$
x_{k+1}=F_{x}\left(x_{k}, y_{k}, z_{k}\right) ; y_{k+1}=F_{y}\left(x_{k}, y_{k}, z_{k}\right) ; z_{k+1}=F_{z}\left(x_{k}, y_{k}, z_{k}\right) \text {, }
$$

where, $F_{x}, F_{y}, F_{z}$ - transformation function coordinates in space that determine the shape of the fractal. Let us consider this method of constructing models of plant objects on the plane using iterated function systems:

$$
x_{k+1}=F_{x}\left(x_{k}, y_{k}\right) ; y_{k+1}=F_{y}\left(x_{k}, y_{k}\right) .
$$

It is necessary to choose a generalized analytical model of the structure of the test plants, which would most accurately describe his architectonic. As an example, consider a symmetric structure relative to the stem with the same angle of inclination relative to the branches (Fig. 1).

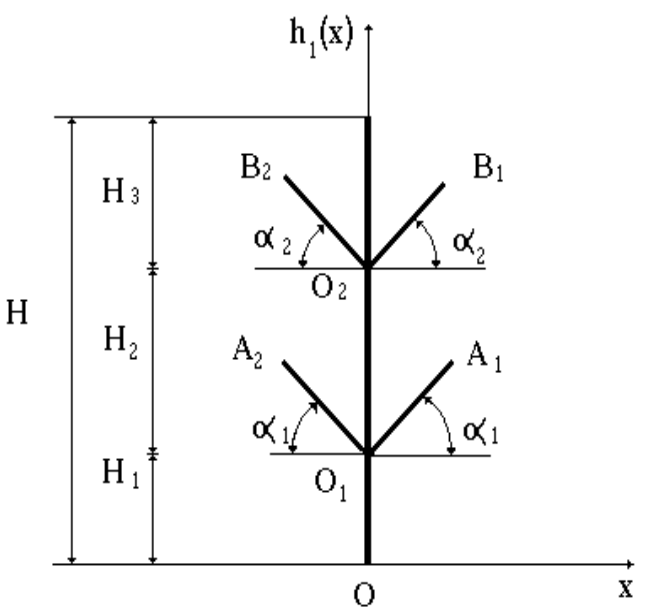

Fig. 1. The symmetrical structure of the model of the plant object.

To begin with the iterations is necessary to set the starting coordinates of the line, the reference points 1 and 2 (Fig. 2). At each iteration step are calculated the coordinates of other points. Point 3 is the result of a turning point by an angle 2 with the center of rotation at the reference point 1 . The points 6 and 7 are obtained as a result of the turning point 5 on the corners $\beta$ and $-\beta$ respectively about a point 4 . 


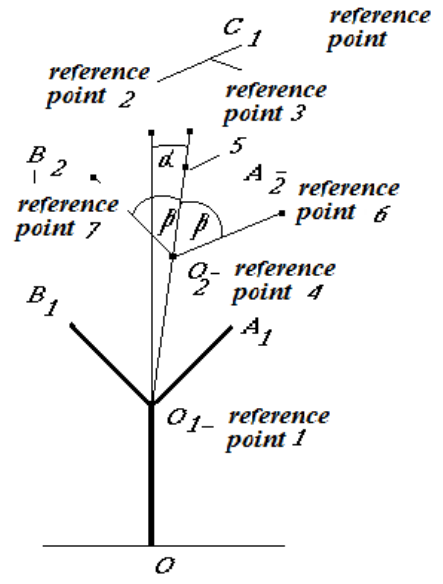

Fig. 2. Fractal model plant object the reference points.

Figure 3 depicts models which obtained by accounts with use iterated functions.
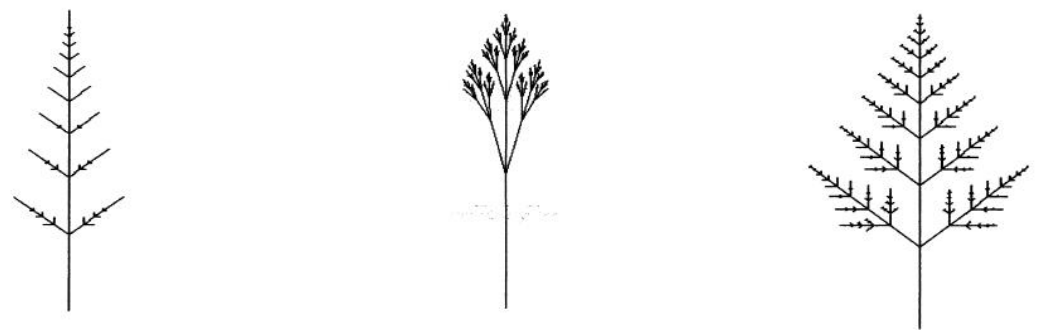

Fig. 3. Examples of construction of symmetric models by using iterated function.

In modeling by using fractals it is necessary to define some rules that is based the structure of the object, for example, the presence of symmetry, the position of the start point of branching, and others.

In order to describe the fractal model need to establish a relationship between the end result and set the initial structure of the object - dynamic law:

$$
x_{k+1}=f\left(x_{k}\right) \text {, }
$$

which can be used not only real numbers, but also complex. The functional dependence may vary over time.

This chapter the methods of fractal geometry are shown in reference points, and you can use the reference architectural forms (objects).

\section{Architectural bionic modeling}

Architectural bionics is a modern science, which considers system: nature - construction people. In this direction, there are forms of architecture associated with nature. Buildings constructed in view of bionic principles have harmony and beauty. Currently, the rapidly developing architectural bionic modeling. The principles and stages of development of this scientific field are considered in $[9,10]$. 
Optimization of building structures using bionic principles helps to create a durable and reliable building constructions of unique architecture [11].

Razdorskiy V.F. are considered plant objects terms of strength. Architects have been using the structure of the design of the structure of plants and other biological structures, and only reminds plant object, but an engineer look makes the construction of unique and harmonious. But we can not Simply transfer the geometric shape of natural objects in the construction, it must be durable, reliable, user-friendly to people and organically fit into the environment. Currently, there is a possibility to use a lightweight aluminum constructions, glass panels, the various shells made of polymer composite materials. So, glass panels for the facade of construction and aluminum panels for the coating are used in creating of the airport "Platov" and of the stadium "Rostov-Arena", Rostov-on-Don (Fig 4, 5).

Natural objects allow them to admire the perfection of form and allow you to apply features of the structure for the design of unique buildings. Of particular interest are the work of world-famous the architects: A. Gaudi, Z. Hadid, N. Forterre, S.Kalatrava, R. Piano.

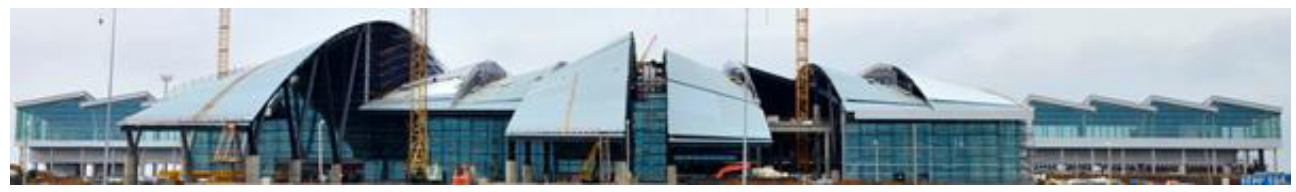

Fig. 4. Airport "Platov", Rostov-on-Don (Russia).

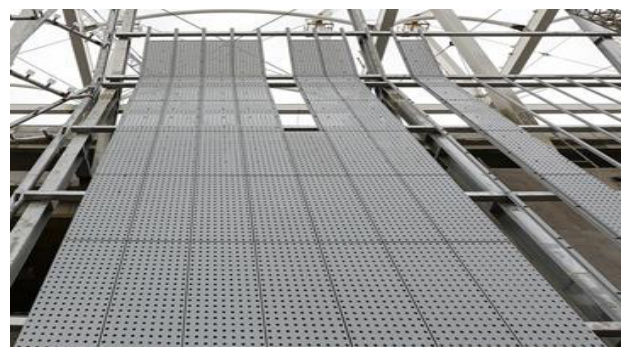

Fig. 5. The element of the facade of the stadium " Rostov Arena", Rostov-on-Don (Russia).

In Baku (Azerbaijan) in the construction of the Cultural Center named after Heydar Aliyev, the world-renowned architect Zaha Hadid has used many different composite designs from modern polymer composite materials (Fig. 6).

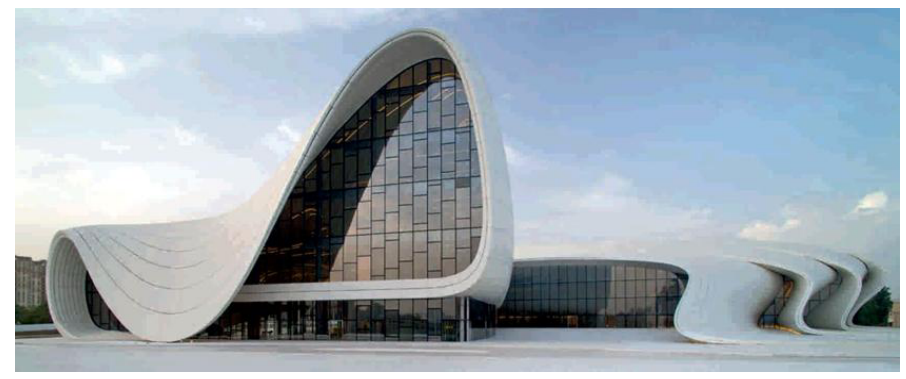

Fig. 6. Cultural Center named after Heydar Aliyev in Baku (architect Zaha Hadid).

Similarly a large drop of water in the urban space - is shopping and entertainment complex "Veltshtadthaus" in Köln (Germany) and the headquarters of Pate Fund in Paris (France). That is imagined buildings architect Renzo Piano. It has many interesting 
solutions, which are based on bionic principles. It is such projects as Zentrum Paul Klee (Bern, Switzerland), the Museum NEMO (Amsterdam, Netherlands), the Museum of Modern Art Astrup Fearnley (Oslo, Norway), Amphitheatre of Lyons (France) (Fig. 7), Skyscraper "Shard" (London, UK) and, of course, the wonderful Cultural center Jean-Marie Tjibaou in Noumea (New Caledonia, French colony).

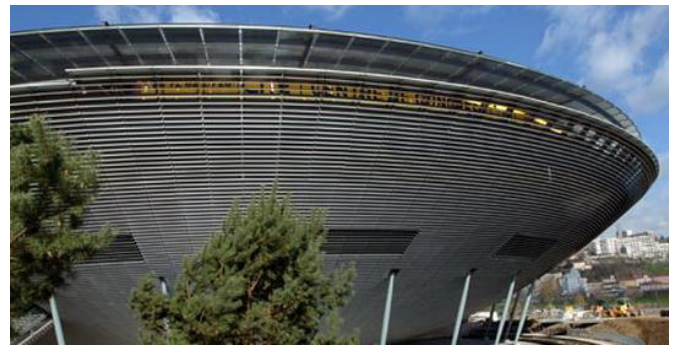

Fig. 7. Amphitheatre of Lyons (France).

Architectural bionic modeling is a synthesis of directions in architecture and interesting natural forms. The current state of scientific and technical base expands potential architects, allows you to create unique structures.

\section{Fractals and architectural forms}

More and more often used in designs of fractal elements and structures in construction. The reason for this consists in that nature has the property of fractality. Mandelbrot in 1975 wrote the work "The Fractal Geometry of Nature"[4, 12,13]. He has introduced the concept "fractal", which means "consisting of fragments that are similar to the whole, and has a fractional dimension." One of the main properties of a fractal is self-similarity.

In this study, it would be desirable to pay attention to such properties as symmetry and fractality. Property of symmetry is very common in nature (Fig. 8).

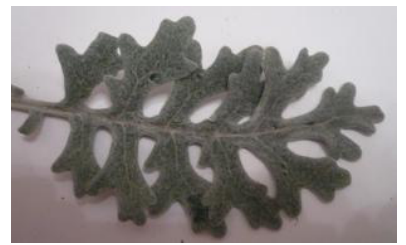

Fig. 8. The plant object with a symmetrical structure.

In Fig. 9 elements spirally arranged with the fractional dimension. Location objects in a spiral is very common in nature, such as seeds of sunflower.

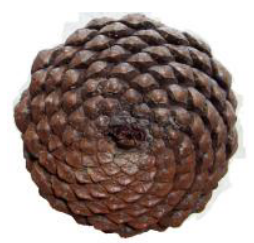

Fig. 9. The plant object with fractal structure. 
We can consider fractal structures for spatial organization of buildings, urban or natural environment, as well as construction of elements or a single natural object. For example, the urban space of the city of Rostov-on-Don (Fig. 10).

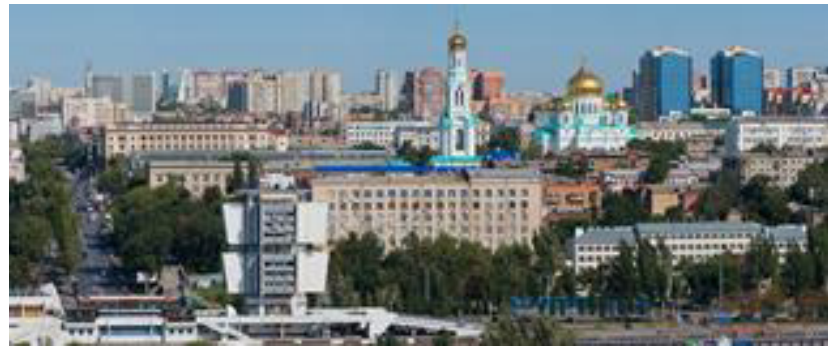

Fig. 10. Panorama of the city of Rostov-on-Don.

Fractals of living nature have a certain number of repetitions, and inanimate - a chaotic structure (nonuniform fractals). Building constructions of geodesic domes (architect RB Fuller) is a fractal structure formed of triangles (Fig. 11). These structures are similar to many biological objects, particularly in microbiology.

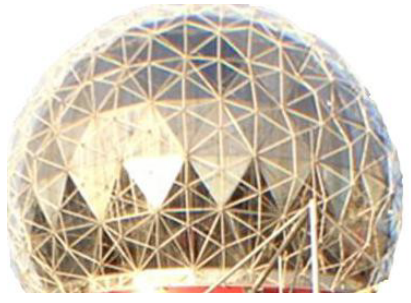

Fig. 11. The design of the geodesic dome.

Application of self-similar forms architecture widespread in the construction of temples, mosques and palaces [8].The properties of symmetry asymmetry and fractallity are appears as whole design and in its elements $[12,13]$.

The coating of the stadium "Rostov-Arena" has a waveform with symmetrical and fractal structures. In Fig. 12 shows a portion of a waveform covering the stadium with arches with fractal dimension.

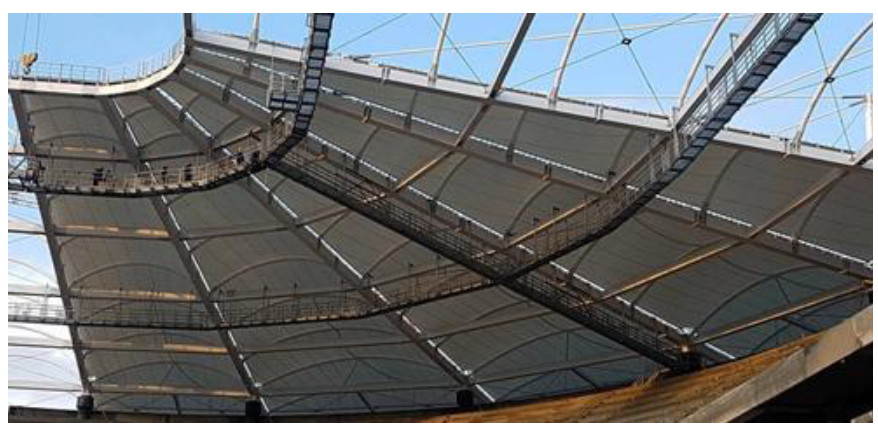

Fig. 12. The element cover the stadium "Arena Rostov" in Rostov-on-Don (Russia).

In the works of masters of the world's masterpieces of architecture we are only looking for harmony and beauty of buildings, conducting analysis with the fractal approach. 
Especially often are considered multifractals. This is a complex fractal structure of several successive construction algorithms with different fractal dimension.

Using the methods of fractal geometry in the design of architectural forms allows you to find a variety of constructive solutions.

\section{The nonlinear architecture}

In the world there are many unique buildings constructed in recent years, in which there are structural elements, like natural objects. It is necessary to develop a scientific field as an architectural bionics. Nature is rich in not only beautiful on the shape of objects, but they are durable, as evidenced by evolutionary processes.

In Fig. 13-15 show various buildings in which there are structural elements of selfsimilar architectural forms. The triumph of symmetry and self-similarity can be seen in the construction of Temple of Lotus in Delhi (India). And asymmetric forms are found in architect Frank Owen Gehry [14, 15].

In the work of architect Santiago Calatrava there are symmetrical and fractal forms in buildings. These structures appear to light and they are unusual in shape. One of the creations of this architect is shown in Fig. 16. In a fractal structure with a logarithmic spiral. A in Fig. 17 we see the plant object like this design.
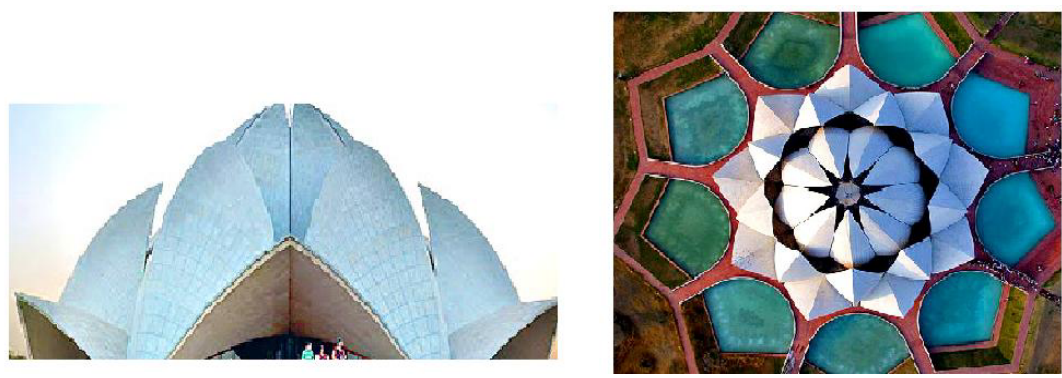

Fig. 13. Lotus Temple in Delhi (India). Side view and from above.

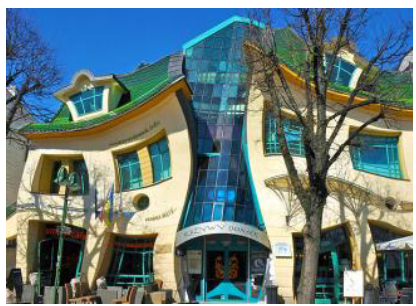

Fig. 14. Shopping center "Resident", the architects Shotinsky and Zalewski in Sopot (Poland).
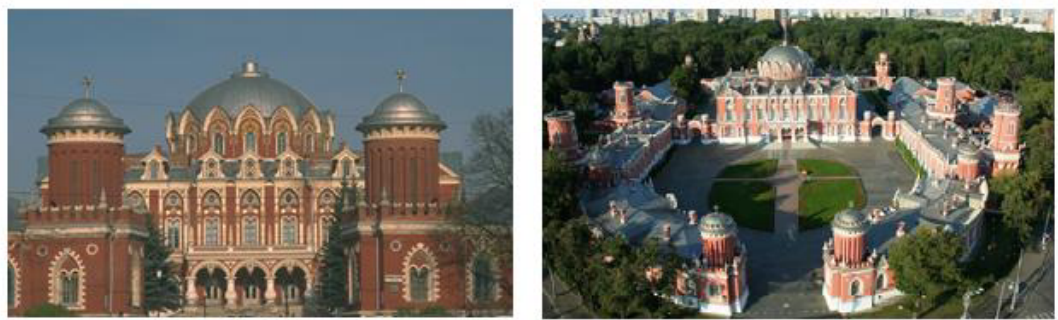

Fig. 15. Petrovsky Travelling Palace in Moscow (Russia). Side view and from above. 


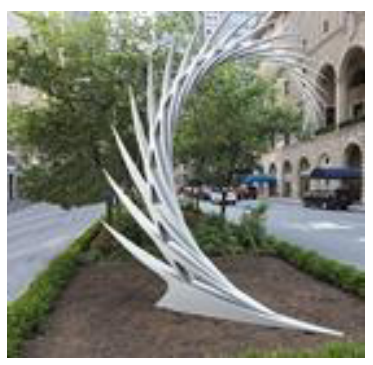

Fig. 16. The design of the architect S. Calatrava.

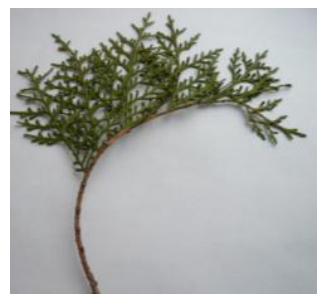

Fig. 17. The branch of thuja.

The development of mathematics and software systems can effectively to implement complex recursive procedure for constructing of fractal models. In mathematical modeling elements of constructions are applied numerical methods of calculation on the strength and reliability of structures. Among them a special place is taken by the finite element method by reason of its universality in program implementation and the possibility of creating a fully automated calculation.

It is necessary to develop methods of architectural bionics, which can be used in the design of buildings and their of structural elements. These methods include the principles of the organization of a biological object, properties, functions and structure of nature.

\section{Conclusion}

Architectural bionics - a style, who takes the best of everything from nature: the reliefs, the contours, the principles of formation and interaction with the outside world. In the world the ideas of architecture of bionic successfully implemented by famous architects.

Demand of man in the native, natural harmony is especially noticeable in recent years. It is necessary not only to surround building structures parks and gardens, but to find such architectural forms, which would give a sense of balance between the natural world and building structures. Such an understanding is developing such a science as an architectural bionics.

Bionics is being implemented in the design of modern buildings. Bionic architecture - it is the reunion of man with the natural living environment. In the construction of such buildings requires knowledge of mathematical and numerical methods for the design.

\section{References}

1. N.A. Saprikina, Basics of dynamic morphogenesis in architecture, 312 (Architecture C, 2005)

2. M.V. Shubenkov, The structural laws of morphogenesis Architecture, 320 (Architecture - C, Moskow, 2006) 
3. M. Kouchner, Future architecture. 100 of the most unusual buildings, 176 (ACT, Moscow, 2016)

4. B. Mandelbrot, The Fractal geometry of nature, 656 (Institute of Computer Science, 2002)

5. A.D. Morozov Introduction to the theory of fractals, 160 (Nizhny Novgorod University, 2004)

6. R.M. Kronover, Fractals and chaos in dynamic systems, 488 (Technosphere, 2006)

7. I.A. Mayatskaya, I.A. Krasnobaev, Nauchnoe obozrenie, 2, 176-178 (2013)

8. I.A. Mayatskaya, B.M. Demchenko, Vestnik VolgGASU Series Building \& Architecture, 30(49), 346-351 (2013)

9. I.A. Mayatskaya, Vestnik VolgGASU Series Building \& Architecture, 45(64), 27-34 (2016)

10. I.A. Mayatskaya, B.M. Demchenko, P.A. Shvetsov, Regional architecture and engineering, Proceedings PenzaSUAC, 2(27), 137-145 (2016)

11. P.P. Gnedich, World architecture, 240 (Publishing house Eksmo-Press, 2012)

12. S.B. Pomorov, A.A. Filippov, Polzunovsky Vestnik, 1, 141-147 (2014)

13. V.V. Isaeva, N.V. Kasyanov, Vestnik DVO RAN, 5, 119-127 (2006)

14. L.Razzhivin, Symmetry (Introduction to the architecture:Vitruvius), 80 (Publishing house RIPOL classic, 2015)

15. A. YU. Mudrova, The great masterpieces of architecture. 100 buildings that are admired the world (Publishing Tsentrpoligraf, 2014) 